\title{
FUNDACIONES DE RELIGIOSAS CARMELITAS EN QUERETARO
}

\section{Por Eduardo Bdez}

La ciudad de Santiago de Querétaro de la Nueva España tuvo, entre las cosas que por notables Zelaa e Hidalgo llamó Glorias de Querétaro: 1 dos casas a conventos fundados por las monjas de la Orden del Carmen, durante la segunda mitad del siglo xvil. Fueron estas casas un beaterio, erigido a mediados de siglo con el título de San José de Gracia, y un convento en toda forma, con regla y clausura, fundado en 1802.

El beaterio de San José de Gracia, tuvo sus origenes en lo que parece haber sido una forma de infiltración disimulada (para eludir los requisitos fijados por el Real Gobierno antes de autorizar fundaciones de nuevos monasterios) de un grupo de señoras que, no pudiendo ingresar a los conventos regulares, se reunian para imitar, hasta donde era posible, la vida monacal. Como no pretendian por entonces una comunidad, podian escaparse a los enfadosos trámites de informaciones y solicitudes ante las autoridades políticas y religiosas.

Las noticias más antiguas de tales reuniones se remontan al año de 1736. Juntábanse a vivir en simple comunidad, sin reglas ni ceremonias, usando el hábito de la religión del Carmen. Había reunido este grupo de mujeres pobres y virtuosas, una que se hacia llamar Maria Magdalena del Espíritu Santo. El sustento se lo procuraban mediante algunos trabajos personales y limosnas que les hacían sus protectores. Originalmente habitaban en unas casas propiedad de una señora llamada doña Ana de Castilla, pero seguramepte constituian una carga para la propietaria, porque ésta terminó por lanzarlas a la calle. ${ }^{2}$

Gracias a que el grupo era pequeño, apenas seis, se acomodaron como pudieron durante algunos días, hasta que el bachiller Diego Javier Colchado Buitrón, presbítero domiciliario, les cedió una casa en la calle de Bethlen, con el fin exclusivo de que la usaran como asilo. 3

El grupo había aumentado, mientras tanto, a nueve, al ingresar entre otras, dos sobrinas del benefactor.

Formaban este primer grupo las siguientes: María Magdalena del Espíritu Santo, María de Cristo, Maria Josefa de Santa Teresa, Francisca

1 Zelaa e Hidalga Jost Ma. Glarias de Quexétoro. Mexica, en la Oficina de Mariana José de Zuñiga y Ontiveros, 1803.

2 Ibid, p. 57.

3. Mtrico, Archivo Genemal de la Nacion, Ramo de Calogios, vol. 21, exp 2, t. 36. 
de San José, Marfa Ana del Padre Eterno, Ana María de San Bartolomé; María de San Miguel, María Antonia de San Alberto, Micaela Jerónima de la Asunción y Salvadora de Ios Santos.

El nuevo alojamiento quedó pronto acondicionado con lo indispensable: Una capilla, un locutorio, la portería y el zaguán.

En el año de 1739 comparecieron ante el juez eclesiástico de la ciudad de Querétaro,' pidiéndole autorización para tener capilla propia, en donde comulgar y oir misa, sin las incomodidades de salir a la calle, pues con menos distracciones, decian que aprovecharfan más en su perfeccionamiento espiritual.

Corrióse el traslado al Promotor Fiscal, respondiendo este funcionario que antes de conceder la licencia solicitada, debian obtener la licencia de fundación para el colegio, ante el gobierno virreinal y la Sagrada Mitra, y se debía asimismo dar vista a los prelados de las religiones mendicantes ya establecidas, y al cura ministro de doctrina de la ciudad, para que expusieran las conveniencias o inconvenientes de la pretendida fundación.

Rindieron dicha información, manifestando no haber inconvenientes para erigir el beaterio, fray Antonio de Villalba, guardián de San Francisco, fray Pedro del Barco, rector del colegio de la Santísima Cruz de Propaganda Fide, fray Juan de Mora, guardián de los Franciscanos Descalzos, fray Agustín de Rivera, rector del colegio de Ermitaños de San Agustín, fray Agustín de la Concepción, prior de los Carmelitas Descalzos y José de Ascaray, rector del colegio de la Compañfa. Al tiempo de fundar el beaterio carmelita existían, en la rama femenina, el Monasterio de Capuchinas, el de Santa Clara y el de Santa Rosa de Viterbo.

Particularmente importante fue el informe del juez eclesiástico, porque distinguía con mucha claridad las diferencias existentes en el espíritu de las Ordenes; por ejemplo, se referia al convento de Capuchinas como a una institución adecuada a los espíritus robustos; al de Santa Clara como a un Instituto para espiritus delicados y tímidos; al de Santa Rosa de Viterbo, como a una institución adecuada para aquellas religiosas cuyas fuerzas no soportaban una regla rigurosa. Aunque en el último se permitía el ingreso de las menesterosas que por falta de dote no podían ingresar en otros conventos, no interferia con el pretendido beaterio; porque para ese tiempo estaba el primero totalmente sobrepoblado.

En suma, vistas las informaciones, el promotor fiscal terminó recomendando la fundación del beaterio como obra de notoria utilidad al bien público, ya que permitiría a quienes no pudieran alcanzar el estado 
religioso pleno, seguir, a lo menos en parte, su vocación religiosa en el seno de una comunidad.

El día 19 de junio de 1739, el deán de la iglesia metropolitana y vicario del arzobispado, don Alonso Francisco Moreno y Castro, en representación del Arzobispo, otorgó la licencia correspondiente a la jurisdicción ordinaria eclesiástica, para constituir el beaterio del Sagrado Carmelo, convirtiendo sus bienes, antes profanos, en espirituales. Se extendia la licencia a tener capilla (que ya tenían hecha) con todos los Sacramentos, con la única condición de que dicha capilla se sujetarfa a una inspección ocular. El día 17 de marzo de 1740, don Juan de Izaguirre, juez eclesiástico y abogado de la Real Audiencia, practicó el reconocimiento, encontrando la capilla adecuada a la institución:

capaz, decente, con grande aseo y que ésta, sin embargo de ser privada y estar dentro de los límites de dicho beaterio o colegio, está retirada de los usos domésticos y en ella hay una reja por donde pueden las susodichas oir misa sin comunicación alguna, afuera y cerca de ella, su cratícula y confesonario. 4

Y todo lo demás necesario para el oficio, como cáliz, patena, 'aras, corporales, vinagreras, cíngulos y purificadores. Un dia después, el 18 de marzo, el mismo funcionario bendijo el oratorio conforme al ritual romano, formalizando la fundación con el título de Beaterio de San José de Gracia.

El 29 de diciembre de 1753, el arzobispo de México, Manuel José Rubio y Salinas, sancionó las constituciones de la comunidad. Anteriormente se habían gobernado por unas reglas, redactadas por el carmelita fray Simón de la Asunción, en forma convencional, pues no estaban autorizadas ni eran cabalmente obedecidas.

En las nuevas constituciones se sujetaba la comunidad al ordinario, estableciéndose como primera regla la obediencia al arzobispo, con la obligación de no alterar sin su licencia ninguna de las cláusulas. Para el vestido, se prescriblan el hábito y el calzado de las Terceras descubiertas de Nuestra Señora del Carmen; establecían la moderación en la comida, el refectorio común, la oración continua, la castidad, la caridad, la obediencia y la mortificación corporal, pues decian que, "siendo los sentidos los conductos por donde entra la ruina del alma; tendrán el espíritu a raya, para que vivan ellos en continua mortificación".

4 lbid., exp. 2, f. 32. 
Para ingresar a la comunidad exigian una edad minima de quince años, y si la aspirante tenía patrimonio, se obligaba a llevar lo necesario para su vestuario y cama, y asegurar sus alimentos.

El número de beatas no podría pasar de 14 y estaría dirigido por una rectora. Para todo lo que no estaba expresamente previsto en las constituciones, se aplicaba supletoriamente la regla de la Tercera Orden de Nuestra Señora del Carmen.

El templo, a pesar de su sencillo origen, no era tan modesto como correspondía a un humilde beaterio. En un inventario practicado entre las diligencias de la fundación, se mencionan los tres siguientes altares:

El Altar Mayor, que ocupaba el lugar principal, tenía un lienzo del Señor San José de dos varas de alto; una imagen de Nuestra Señora del Tránsito de vara y media de altura, con corona de plata y vestido de damasco; una escultura de Santa Teresa y cuatro niños Jesús.

El segundo altar, de las Animas, tenfa una imagen en talla de Jesús Nazareno, con sus tres túnicas, una que era de Pekin y dos de melendra; una talla de la Virgen de la Piedad, un Ecce Homo, una imagen de Nuestra Señora de la Luz y otra de San Gregorio.

El-tercer altar, del Santo Cristo, tenía un Jesús Crucificado, una imagen de Nuestra Señora de los Dolores, una imagen de San Juan, una de San Pedro, un San José y un Via-Crucis. ${ }^{5}$

Para 1768, el arzobispo Lorenzana estableció en el beaterio la enseñanza de niñas, erigiéndolo en Colegio Real de Enseñanza, por cédulas de 7 de junio de 1791 y 16 de febrero de 1800. Con esta mutación, abandonaban sus moradoras la regla de Santa Teresa para adoptar la de San Agustín, no quedando los de carmelitas sino el nombre. Al mismo tiempo, el monarca las autorizaba para que levantaran un nuevo templo, el cual se terminó y dedicó, con toda solemnidad, el 20 de julio de 1802. Medía más de 32 varas de largo, con sacristía y piezas anexas; era de bóveda y había estado bajo el cuidado del marqués del Villar del Aguila. *

El edificio dejó el nombre a la calle, que primero se llamó calle de Santa Teresa y más tarde calle de Carmelitas. 7

Otra calle, que tenía entrada a una pertenencia del convento o beaterio llamóse también, por este hecho, calle de la Enseñanza, ${ }^{8}$ por alusión

- rbid, exp. \& L 56

6 Zelaa e Midalgo, op. cit., p. 58.

7 Frias y Frias, Valentín. Las calles de Queretaro. Qro., Imp. Demetrio Contreras, 1910, p. 113.

8 Ibid., p. 114. 
4 esableciminente de 12 enseñanza religiosa decretada por el arzobispo Lorenzam.

La segunda fundación, sin duda más importante que la anterior, fưe la del convento de religiosas carmelitas cuya historia, narrada en forma suscinta, es como sigue:

Tuvo el monasterio su origen en la devoción y desdicha de doña María Antonia Gómez Rodriguez de Pedroso, marquesa de Selva Nevada, una de las damas más acaudaladas de la Nueva España, y con tantas riquezas como frustraciomes.

Era viuda de don Manuel Rodríguez de Pinillos, de quien habia tenido cinco hijos, cuatro mujeres y un varón. Dos de las hijas habían escogido la vida religiosa, profesando en el convento de San Jerónimo $e$ instituyendo heredera en todos sus bienes y derechos a la misma marquesa. En cuanto al único hijo, habia fallecido, "en lo más floreciente de la edad", de manera que únicamente dos hijas quedaban a doña Marfa Antonia. La mayor tenfa contraído matrimonio con José Gutiérrez del Rivero, viviendo sólo la menor, llamada doña Joaquina, en compañia de la señora marquesa.

Como pareció grande el caudal para sólo una viuda amargada y una hija que la acompañaba, acudieron pronto y oportunamente las religiosas carmelitas, para enterarlas del proyecto que tenian de fundar un convento de su Orden en la ciudad de Querétaro y de que solamente las detenía la pobreza de sus fondos. No necesitó ofr más la Marquesa de Selva Nevada para inclinar su voluntad, aceptando el compromiso de costear de su peculio los gastos para la pretendida fundación, ofreciendo, desde el primer momento, hacer el donativo de una suma que oscilaba entre 65 y 70,000 pesos.

En los días en que se trató de la fundación, la fortuna de la marquesa, ascendía, según inventario de sus bienes, a la cantidad aproximada de 620,000 pesos, suma impresionante para la época. Integraban este capital las siguientes propiedades: las haciendas de San Borja, Jesús del Monte y Venta de Tablas; las haciendas de Santa Rita y del Saúz del Magueyal, en ta jurisdicción de Zempoala; las de San Jerónimo, San Lucas, San Antonio y Santa Rosa, en jurisdicción de Tepeaca. El rancho de Santa Inés en la jurisdicción de Otumba y el de San Luis en la de Apan. En la ciudad de México, una casa en la calle de la Cadena y otra que se iba fabricando en la Rivera de San Cosme, con un terreno anexo plantado 
de olivos. Finalmente, también en la ciudad de México, varias pulquerías. Por lo visto, esta aristocracia colonial, que para enumerar sus títulos podía llenar renglones, no despreciaba, ni por un momento, los ingresos poco edificantes provenientes de negocios censurables como las pulquerías. Consta en el inventario, que pertenecían a la marquesa de Selva Nevada las pulquerfas de La Garrapata, La Retama, Cantaritos y Granaditas.

Los detalles para la fundación estaban concertados desde 1797, entre la benefactora y las religiosas del convento carmelita de San José de Gracia. La donadora se obligaba a construir la iglesia y el convento, con arreglo a las constituciones de la Orden; se obligaba también a pagar una dote de 4,000 pesos a tres de las monjas fundadoras; a pagar la renta del capellán, los gastos de la sacristía y el aceite para la lámpara. Obtenía, en cambio, el patronato de la iglesia, para ella y sus sucesores, en el título de Marqueses de Selva Nevada, con la única salvedad de que, muerta la hija mayor, doña Teresa, la sucedería en el patronato, aunque no en el título, la hija menor doña Joaquina. Cada uno de los parientes de la marquesa, lo mismo que ella, gozarían en su sufragio de los actos religiosos que se hicieran en el convento en determinados dias.

A mediados de 1797 compareció la marquesa ante el virrey solicitando formalmente la licencia para la fundación. En su ocurso puntualizaba varios detalles, por ejemplo, ofrecía aumentar la donación todo lo necesario, en el caso de que el costo de la obra sobrepasara su primer ofrecimiento; que el convento quedaría moderado a las veintiún religiosas que permitian las constituciones y que las fundadoras tendrian que salir del convento de San José de Gracia de México. Tenía tratado también, en la Real Academia de San Carlos, el proyecto para el monasterio, aunque hacía la aclaración pertinente de que no se había procedido aún a levantar los planos correspondientes, por no haber querido comprar los predios necesarios, hasta conocer el sentido de la resolución del monarca.

En la larga exposición de los motivos y ventajas que favorecían a la fundación, la marquesa pretendía pisar por el mismo camino que Santa Teresa de Jesús, y así como la mística española había combatido dos siglos atrás a los herejes luteranos, reformando la Orden del Carmelo, la acaudalada marquesa invertía su fortuna en fundar conventos de monjas carmelitas, asumiendo la defensa de un mundo que de viejo y corrompido se desplomaba. Sólo unos pocos años antes, los gobiernos surgidos de la Revolución francesa hablan nacionalizado los bienes de la 
iglesia y suprimido, por inútiles, las congregaciones religiosas, horrorizando a los espíritus medrosos como el de la marquesa, que suplicaba al Rry en los siguientes términos:

Creo que será del agrado de su Majestad, que cuando en otros reinos se están destruyendo los conventos de religiosas, en los suyos y por sus vasallos de las Indias, se trate de aumentar los que hay, edificando otros de nuevo, donde las virgenes se ocupen continuamente en alabar a Dios y pedirle por la salud y felicidad de su soberano y de su Real familia. 9

El arzobispo Núñez de Haro y Peralta concedió su licencia, no así el Fiscal de lo Civil, que desahogando la vista objetó incidentalmente el proyecto, con base en que se violaba el artículo 70 de la Real Ordenanza de Intendentes, al no acompañar a la solicitud los planos y el presupuesto para la obra.

El texto del ordenamiento citado era el siguiente:

Cuidarán asimismo los Intendentes de que en ningún pueblo de los de su mando se construya iglesia alguna, ni otro edificio público, sin que preceda qque los dibujos de sus planes, alzados y cortes se les presenten, para que remitiéndolos a la Junta Superior, ésta los haga examinar por ingenieros o arquitectos, y rectificados por ellos en la parte que lo exijan y mire a la mayor firmeza y duración de la obra, como a la hermosura, buena distribución y demás partes que recomienda la facultad, proponiendo también los medios que conceptúen más adaptables al logro de los proyectos que se formen, con proporción al gasto que quieran o puedan hacer las personas o ramos que los costeen, recaiga la aprobación de la misma junta. 10

Aunque la marquesa se reservaba exhibir los planos y el presupuesto hasta obtener la licencia del soberano, el fiscal objetaba que, supuesto que la iglesia tendría que construirse con las mismas medidas que tenía la de San José de Gracia de México, se podría proceder a un avalúo previo, tomando como base el mayor valor de los predios de la capital respecto a los de Querétaro.

En el mes de octubre de 1797, la marquesa presentó un nuevo escrito, acompañado de los planos y presupuesto para el monasterio, con el objeto de llenar los requisitos del expediente. Aclaraba en él que los planos no estaban arreglados a las dimensiones del convento de San José de Gracia, porque jamás había ofrecido ni propuesto, fabricar una obra

A.G.N., Historia, vol. 77, f. 52.

10 A.G.N., Ordenanzas, vol. 20, l. $80 \mathrm{v}, 81$. 
tan grande como ésa, sino una iglesia y convento arreglado para veintiún religiosas. Otro infausto acontecimiento agudizaba la urgencia con que la marquesa solicitaba la real autorización y era que, en el lapso transcurrido desde que había formulado su primera petición, habia fallecido su hija doña Joaquina, dejándole en mayor libertad para invertir su dinero y en más necesidad de procurarse el auxilio espiritual, para su alma y las de sus hijos, que no habían disfrutado su caudal en vida. La muerte prematura de doña Joaquina alteraba las disposiciones sobre el patronato, variándolas la testadora en el sentido de que, si llegara a faltarle descendencia directa y el marquesado pasaba a líneas colaterales, el patronato del convento recaería en su hermano don Juan Vicente Gómez, en forma vitalicia, y a su muerte pasaría a la misma comunidad de monjas que se pretendia fundar.

Vistos por el Fiscal de lo Civil, se pasaron los planos a examen a la Real Academia de San Carlos. El autor del proyecto y del presupuesto era don Manuel Tolsá, director de escultura de la misma Academia y académico de mérito en el ramo de arquitectura. Examinados en junta ordinaria, se aprobaron por unanimidad de votos el 31 de octubre de 1797.

Así, integrado el expediente, se pasó en el mes de noviembre al Supremo Consejo de Indias.

Pero, contra todos los deseos de la marquesa y esperanzas de las carmelitas, por Real Cédula dada en San Lorenzo en 10 de diciembre de 1798, el monarca, previa consulta con el consejo, denegó la licencia. Fundaba su negativa en que ya tenía la ciudad de Querétaro un beaterio de carmelitas descalzas, que no existía la urgencia prevista por la ley para autorizar nuevas fundaciones y que Querétaro tenía suficientes conventos de religiosas.

Con un sentido muy atinado de humanitarismo, el monarca recomendaba, al virrey y al arzobispo de México, que procurasen inclinar a la marquesa a gastar su dinero en obras útiles como la crianza de huérfanas, hospitalidad y socorro de doncellas y de indios pobres, de todo lo cual habia mucha necesidad en sus dominios.

Cuando la resolución Real se conoció en la Nueva España, a mediados de 1799, se presentó un problema jurídico: La marquesa había renunciado a su título al profesar en el convento de Regina de México, desde fines de 1798, en donde vivía como sor Marfa Antonia de los Dolores. En sus disposiciones testamentarias, dejaba señalados como albaceas a su hija y a su yerno, nuevos Marqueses de Selva Nevada, a su hermano 
don Juan Vicente Gómez Rodríguez de Pedroso, al canónigo don Juan José Gamboa y a don Juan Antonio Llata.

En la cláusula décima del testamento, previendo que el rey negara la licencia para fundar, instruía la exmarquesa a sus albaceas que no desistieran, sino que acudiesen por una segunda y tercera vez, por todos los medios y arbitrios oportunos hasta conseguir la licencia, y aun en el caso de que el rey la negara hasta tres veces, que dejando correr el tiempo de diez años, volvieran a intentarlo como si nunca antes lo hubieran pedido. Si ni con todo este empecinamiento se ganara la real voluntad, quedaba prevenido, en otras cláusulas, el destino de los caudales. La fortuna se repartiría aplicando a la nueva Marquesa de Selva Nevada la suma de 40,000 pesos, y lo demás en capellanías eclesiásticas y dotes para religiosas.

Los albaceas recurrieron al fiscal interpretando con mucha elasticidad la Real Cédula. Por principio de cuentas, desestimaban la recomendación de inclinar a la exmarquesa a auxiliar con su dinero a los indios pobres y a los huérfanos, toda vez que al profesar, decían que quedaba para el siglo como si hubiera muerto, incapaz de ejercitar actos de dominio sobre bienes a los que había renunciado en forma irrevocable. En cuanto a obras piadosas, alegaban ser muchas las que la exmarquesa tenfa realizadas, y que socorro de doncellas lo era también el dotarlas para ingresar en un convento. Para el beaterio de carmelitas de Querétaro, solicitaban se practicara una información sobre su instituto y funcionamiento, y que lo mismo se hiciera en los conventos de recoletas de aquella ciudad. Finalmente pedían que los conventos de carmelitas de México manifestaran el número de religiosas que albergaban y el número de las que a ellos pretendian ingresar.

Los albaceas justificaban la pretendida fundación, insistiendo en que si los conventos de "velo blanco" o mitigados resultaban escasos, los de recoletas, en que se observaba con todo rigor la vida en comunidad, no sólo eran escasos sino exiguos. En la capital, por ejemplo, de recoletas únicamente lo eran el de Santa Brígida, Capuchinas, Santa Teresa la Nueva y San José de Gracia, que no bastaban para acoger sino a las señoras de la ciudad, quedándose las forasteras frustradas en sus anhelos religiosos. Calculaban los albaceas que el número de religiosas en todo el reino no llegaba a dos mil cien, suma desproporcionada para siete mil doscientas doncellas que, por incasables, significaban aspirantes a los conventos. Esta falta de plazas conventuales se agravaba por lo pequeño que resultaban, ante el número de pretendientas, las vacantes que queda. 
ban por muertes, no faltando ejemplos de aspirantes que pasaban hasta catorce años, antes de conseguir su admisión en algún claustro, o de otras que fallecian, sin haberla logrado a pesar de todos sus años.

Aunque se puede suponer exagerada la afirmación de los albaceas, no carece de verdad; en las listas remitidas por los conventos de Santa Teresa la Antigua y Santa Teresa la Nueva, en cuyos claustros vivían hasta veintiún religiosas, aparecen treinta y nueve pretendientas para el segundo, con una sola vacante ocurrida por muerte en los últimos diez años, y para el de Santa Teresa la Antigua aparecen cuarenta pretendientas, con sólo seis vacantes ocurridas en los últimos veinte años. Tenían razón las superioras, al afirmar en sus informes, que la vida en los conventos hacia a las monjas "buenas vividoras".

En el informe rendido por el corregidor de Querétaro, aparecían cuarenta y cuatro pretendientas para el convento proyectado.

Estudiada la petición por segunda vez, en el Supremo Consejo, pero en esa ocasión con toda la información necesaria, el monarca concedió la licencia mediante una Real Cédula dada en Aranjuez el 25 de junio de 1802, considerando que las circunstancias habían variado desde la expedición de su cédula anterior de 1798. Verdaderamente no eran tales circunstancias las que ocasionaban la mudanza de la voluntad Real, sino la intervención del confesor del rey, el reverendo padre Fernando Scio, con quien sostenía correspondencia don José Gamboa, albacea de la ex marquesa de Selva Nevada. Llegó la esperada cédula a la Nueva España, en octubre de 1802, celebrándola los conventos carmelitas con "repiques a vuelta de esquila".

El marqués de Selva Nevada y el canónigo José Gamboa no perdieron el tiempo, porque sabiendo que la construcción del monasterio tardaria varios años, acudieron ante el virrey con la súplica de que les permitiera fundar el convento en forma provisional, en un par de casas contiguas y bien aderezadas, que con ese fin habían arrendado en la ciudad de Querétaro, previa conformidad del Promotor Fiscal, del arzobispo y de los capellanes de Santa Teresa, que no encontraban inconveniente en que se procediera a la fábrica provisional. Estas casas estaban ubicadas en la calle de Posadas (después $2^{n}$ de Pasteur), junto al mesón de San Antonio. ${ }^{11}$

Los preparativos para la instalación se iniciaron de inmediato desde la capital. El 12 de abril de 1803, el arzobispo Lizana acudió al convento

11 Frias y Frias, Valentin. Leyendas y tradiciones queretanas. Qro., Imp. de la Escuela de Artes de Señor San José, 1900, p. 306. 
de Regina Coeli de México, para trasladar a sor Maria Antonia de los Dolores, a Santa Teresa la Antigua, en donde recibió el hábito de las novicias carmelitas descalzas, llamándose en adelante María Josefa de Santa Teresa. ${ }^{12}$

De Santa Teresa la Antigua partió la nueva religiosa en compañía de otras de la misma orden, que eran María Bárbara de la Concepción, Marja Ignacia de San Elías, María Eufrosina de San Juan Bautista y María Clara de San Elíseo. En los alrededores de Querétaro, en su hacienda de Las Carretas, las recibiría don Juan Antonio del Castillo y Llata, comandante del cuerpo de caballería de Sierra Gorda.

El 21 de abril entró el arzobispo en la ciudad, que tenía preparada una solemne y ruidosa recepción, y el 22 , por la mañana, comisionó al doctor Juan José de Gamboa para que bendijese el convento provisional. Ese mismo día, como a las 10 de la mañana, llegaron en carruaje las monjas fundadoras, hospedándose en el convento Real de Santa Clara, en espera del arzobispo, que las conduciría a las casas improvisadas en convento.

La Gaceta de México del 6 de mayo de 1803, describe con lucidez la procesión que entonces dio principio, acompañada la música de una orquesta, entre las calles queretanas adornadas de cortinas, arcos, flores y gallardetes:

Por su orden, abrían la marcha las cofradías, con sus insignias y estandártes; seguíanlas, según su antigüedad, las comunidades de Hospitalarios, de la Caridad, de la Merced, carmelitas descalzos, agustinos y franciscanos. En seguida pasaron en imagen San Francisco y Santa Clara, que venian por padrinos; los frailes predicadores y el clero secular, llevando en andas de plata un Niño Jesús, que para patrón del convento habían traído las religiosas. Estas seguían en la procesión, acompañadas de sus madrinas, sosteniendo velas encendidas y crucifijos. Luego venía el Santísimo Sacramento, bajo de palio, conducido por el arzobispo, vestido de alba y capa pluvial. Al final caminaban los miembros del ayuntamiento, bajo de mazas, el canónigo de la Colegiata de Guadalupe, el Marqués de Selva Nevada, don Juan José Gamboa y don Antonio del Castillo y Llata. Cerrando el cortejo, cumpliendo con una costumbre que hasta nuestros días se practica, marchaba detrás de la columna una compañía de granaderos del Regimiento Provincial, "con toda su música". ${ }^{13}$

12 Ibid., p. 307 .

1s Suplemento a la Gaceta de México del viernes 6 de marzo de 1803 . Tomo xı. núm. 35, p. 285. 
Los planos para esta casa provisional, existen en el Archivo General de la Nación, en el volumen 77 del ramo de Historia, fojas 179-80.

El primero, en el folio 179 , de 47 por $63 \mathrm{cms}$., sin acotaciones ni escala, representa la planta baja; están registradas en él la iglesia, con una puerta a la calle, la sacristía interior y exterior, claustro procesional, patios, cocina, sala de Profundis, refectorio, porteria interior y exterior, sala para archivo, fregadero, rejas y torno. El coro bajo se situaba al lado del Evangelio, hacia el presbiterio, sin más comunicación con la iglesia que la cratícula y la reja.

El segundo en la foja 180 , con las mismas medidas y falta de escala, dibujado en tonos rosa y amarillo, representa la planta superior, en la que se advierten ocho celdas para profesas, cuatro para novicias, enfermerfa, dormitorios y cuarto para la subpriora. En éste, como en el anterior, aparece una media rúbrica ilegible.

A primera vista, se nota que se trata de un convento improvisado en cásas particulares, por la irregularidad con que están distribuidos sus elementos principales.

En marzo de 1803, el corregidor Miguel Dominguez hizo una inspección para comprobar la correspondencia de los planos con la casa, y con sólo dos ligeras modificaciones, al cambiar de lugar la sala de profundis y la escalera del coro alto, encontró que la obra llenaba las necesidades de un pequeño convento. Tenfa agua limpia y suficiente, y aunque contigua al mesón de San Antonio, habían tenido la precaución de resguardar la casa elevando las tapias y ubicando la iglesia, coro y habitaciones de religiosas, lo más lejos posible del mesón.

En esta casa estuvieron las carmelitas descalzas hasta el año de 1807, en que se trasladaron a su nueva morada.

El monasterio definitivo se había iniciado el 24 de junio de 1803, fecha en que habian colocado la primera piedra con la ceremonia de costumbre.

De acuerdo con el ofrecimiento de la exmarquesa, el edificio se levantaría según el proyecto trazado en 1797 por Manuel Tolsá, que era el aprobado por la Real Academia de San Carlos, remitido a España en el expediente en que solicitaban la licencia de fundación. Estudiado el asunto en el Supremo Consejo, y otorgada la licencia, los planos pasaron a engrosar el acervo del Archivo de Indias.

La primera noticia de estos dibujos se debe a Pedro Torres Lanzas, en 1900, que proporcionó la referencia en su Relación descriptiva de los 
mapas, planos, etcétera, de México y la Florida, existentes en el Archivo de Indias. 14

Posteriormente los publicó Diego Angulo fñiguez, en Planos de monumentos arquitectónicos de América y Filipinas, existentes en el Archivo de Indias, 15 acompañándolos de una nota explicatoria sobre la fundación del monasterio.

Los trabajos subsecuentes que han tocado esta materia, se han apoyado invariablemente en las fuentes anteriores. En este artículo, publico una vez más los planos, pretendiendo su originalidad no en la divulgación sino en la fuente, pues en esta ocasión se han fotografiado de originales "que se custodian en México, en el Archivo General de la Nación. ${ }^{16}$

Cuando don Manuel Tolsá sometió su proyecto para el convento al examen de la Real Academia de las Bellas Artes, presentó sus planos por duplicado, y una vez que fue aprobado, se remitió un ejemplar a la Península, con todo el expediente de la fundación, quedando el otro en la.Secretarfa del Virreinato.

El proyecto de Tolsá contiene cuatro planos: El primero con dos dibujos, uno para el alzado de la fachada y otro de un corte longitudinal del monasterio, partiendo por enmedio la nave de la iglesia; el segundo plano contiene la planta alta del convento, y el tercero la planta baja. Las acotaciones están en varas y en escala de treinta varas igual a $17.5 \mathrm{cms}$.

El primer dibujo, con el alzado de la fachada, indica un frente para

14 Torres Lanzas, Pedro. Relación descriptiva de los mapas, planos, etc. de México y Floridas, existentes en el Archivo de Indias, vol. 2, p. 119-20, núm. 472-4.

Plano de la parte baja del convento de religiosas Carmelitas Descalzas que proyecta

fundar en Querétaro la señora Marquesa de Selva Nevada. Por don Manuel Tolsá.

Con expediente y carta No. 262 del Virrey de Nueva España, Marqués de Branci-

forte, de 30 de septiembre de 1797. Con explicación. Escala de 30 varas castellanas

los $17.5 \mathrm{~cm} .60 \times 43 \mathrm{~cm}$. Estante 97, cajón 1, Legajo 21 (4).

Plano de la parte alta del convento de religiosas Carmelitas Descalzas que proyecta fundar en Querétaro la señora Marquesa de Selva Nevada.

Por don Manuel Tolsá. Con expediente y carta No. 262 del Virrey de Nueva España Marqués de Branciforte de 30 de septiembre de 1797. Con explicación. Escala de 30 varas castellanas los $17.5 \mathrm{~cm} .60 \times 43 \mathrm{~cm}$. Estante 97, cajón 1, Legajo 21 (5)

Plano de la fachada y de un corte tirado por la linea $A B$ del plano del convento de religiosas Carmelitas Descalzas que proyecta fundar en Querétaro la señora Marquesa de Selva Nevada.

Por don Manuel Tolsá. Con expediente y carta No. 262 del Virrey de Nueva España, marqués de Branciforte, del 30 de septiembre de 1797. En colores. Escala de 30 varas castellanas los $17.5 \mathrm{~cm} .59 \times 41 \mathrm{~cm}$. Estante 97, cajón 1 , Legajo 21 (6). 15 Angulo Iñiguez, Diego. Planos de monumentos arguitectónicos de América y Filipinas existentes en el Archivo de Indias. vol. 1, p. 224-9.

18 A.G.N., Templos y conventos, vol. 18; Historia, vol. 77, f. 179-80. 
todo el monasterio de setenta y dos varas, de esquina a esquina, con la iglesia en el centro, con un ancho en su fachada de catorce varas.

El alto del muro exterior alcanza trece varas y media, no considerando los edículos que flanquean la iglesia. El conjunto es sobrio y simétrico, con el muro dividido en dos cuerpos por una cornisa; el cuerpo superior es completamente liso y el inferior sólo se abre en los pequeños rectángulos de las ventanas y puertas para las accesorias exteriores.

La iglesia tiene una altura de veintiuna varas y media hasta la bóveda, y tres más la cruz de remate, logrando casi, en relación con su ancho, la proporción sesquiáltera.

Dos päres de pilastras toscanas flanquean la puerta, apoyados en un zócalo, sosteniendo un entablamento líso. El único adorno, en este conjunto geométrico, es el escudo del Monte Carmelo, sobre el arco de ingreso, con dos guirnaldas neoclásicas pendientes. En el cuerpo alto, también entre pilastras toscanas pareadas, tiene un nicho con la estatuilla de un santo. A ambos lados de la fachada se elevan dos edículos, rematados en crucesillas.

El segundo dibujo, en el mismo folio, muestra en corte longitudinal un interior adintelado, con pilastras jónicas, y una nave dividida en tramos cerrados con bóvedas esféricas. El altar del presbiterio lleva columnas corintias y los nichos laterales la guirnalda neoclásica.

El segundo plano contiene la planta superior. La iglesia consta de tres tramos, apreciándose el coro alto notablemente amplio, comunicado con el antecoro. Tiene exactamente veintiún celdas para profesas, con arreglo a las constituciones, en el claustro alto, y cinco más para novicias. Hay asimismo una sala para los nacimientos navideños, otra para recreación, un oratorio, una pieza para archivo, botica, enfermería, ropería, piezas varias y soleadas azoteas.

El tercer plano corresponde a la planta baja. Es una planta casi cuadrada, de 63 por 72 varas castellanas; al centro y al frente la iglesia, cuyos ejes miden, entre los muros, 11.14 por 32.74 varas. Al lado derecho del presbiterio, quedaba situado el coro alto. La iglesia se comunicaba con la sacristía y el gratulatorio. Tiene la planta cuatro claustros, siendo el procesional muy despejado, con una fuente circular al centro.

A la izquierda de la iglesia seguía la portería exterior, comunicada con el interior del convento sólo por un torno, y a la derecha la reja exterior.

Sin comunicación con el interior, dando sobre la vía pública, tenía una accesoria para el sacristán y otra para la mandadera. Por el contrario, 
DOI: http://dx.doi.org/10.22201/iie.18703062e.1968.37.862

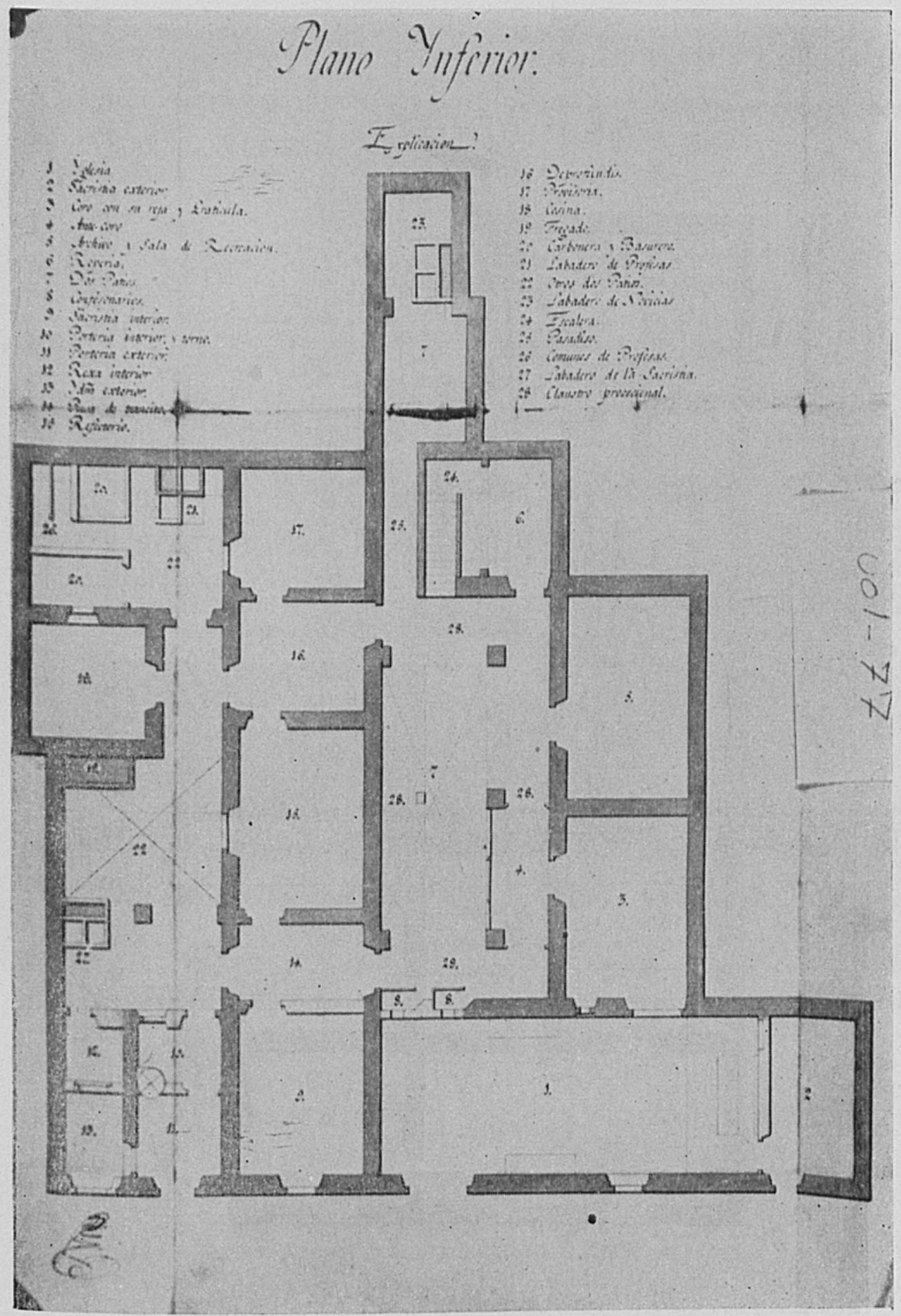

1. Plano para el convento provisional de religiosas carmelitas en Querétaro 
Flane Superiar

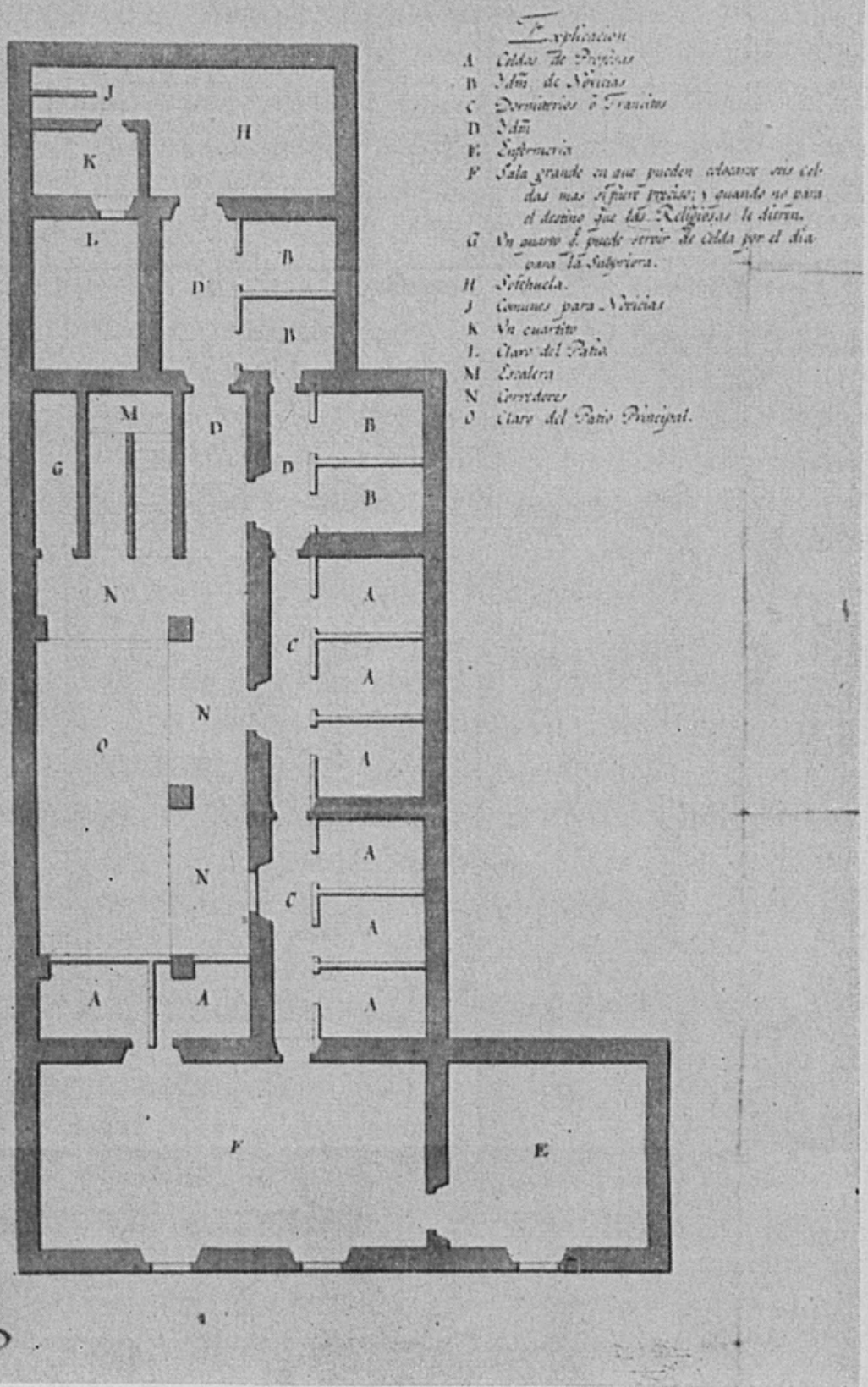

2. Planta superior 
DOI: http://dx.doi.org/10.22201/iie.18703062e.1968.37.862

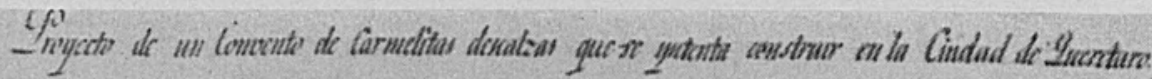

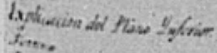

the

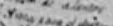

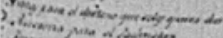
Tonas

Hidnon of rewat Midnotion

.

trivicent

i.ton-4 and

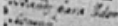

intoris

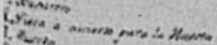

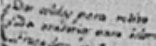

Everesing in is

\section{n.}

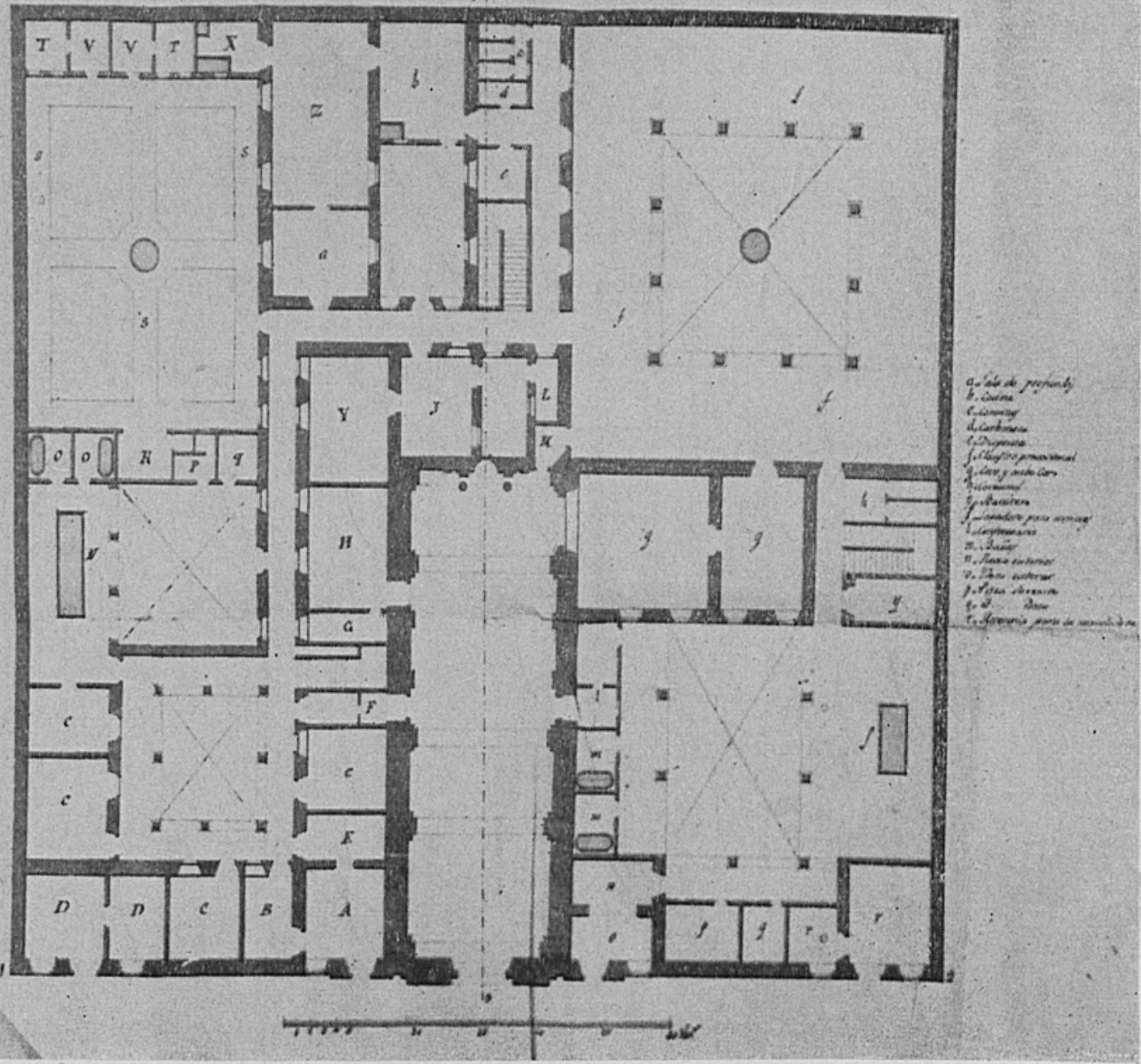

3. Proyecto de Manuel Tolsá para el convento de religiosas carmelitas en Querétaro 
DOI: http://dx.doi.org/10.22201/iie.18703062e.1968.37.862

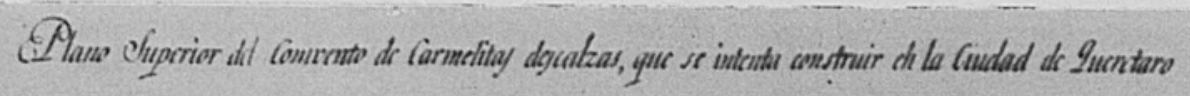

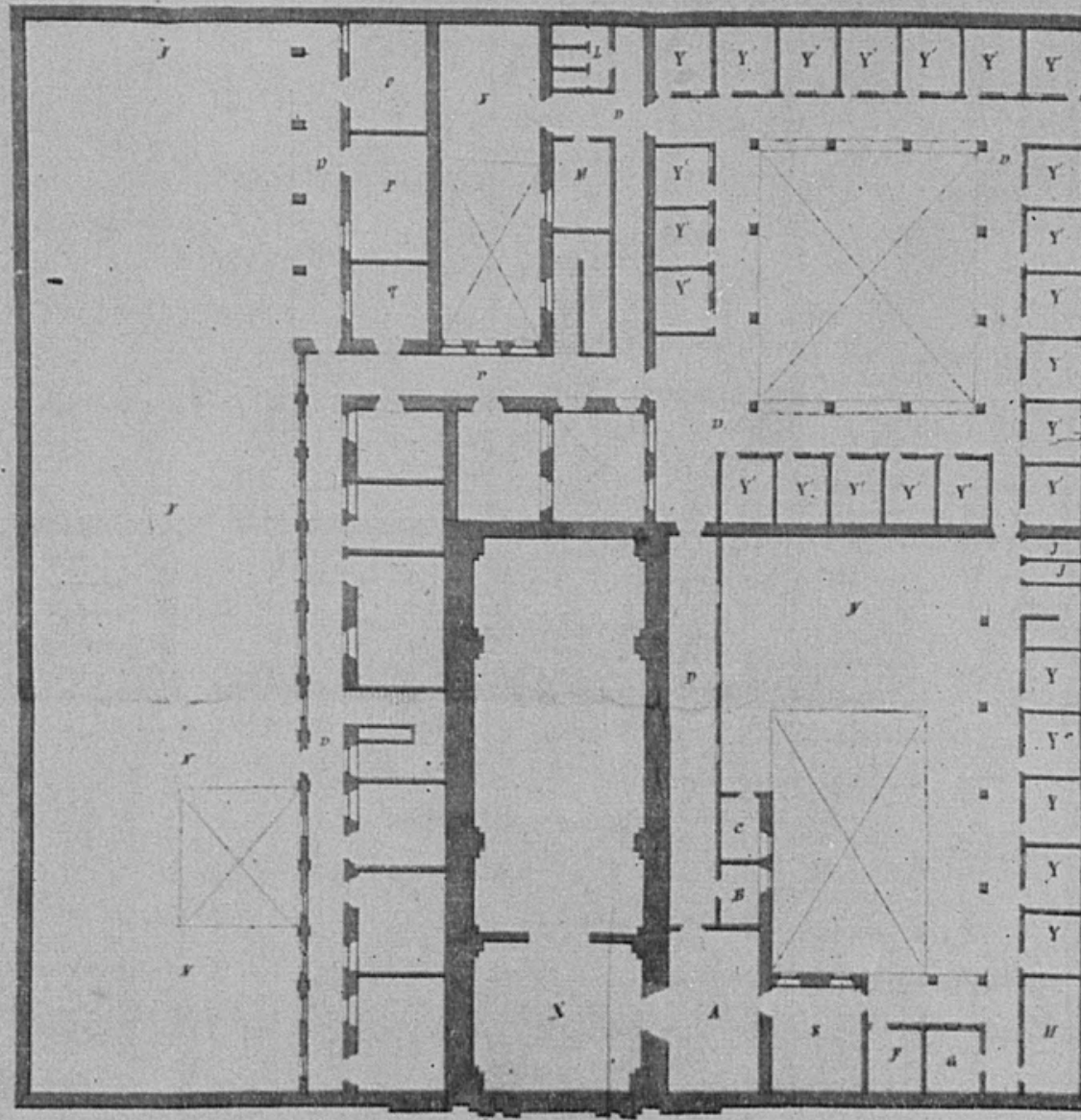

$\lim$

3. 20

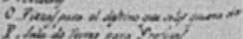

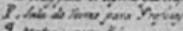

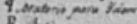

S. $\sin$

Tras.

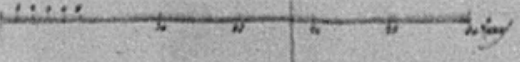

4. Proyecto de Manuel Tolsá para el convento de religiosas carmelitas en Querétaro. Planta alta 
DOI: http://dx.doi.org/10.22201/iie.18703062e.1968.37.862

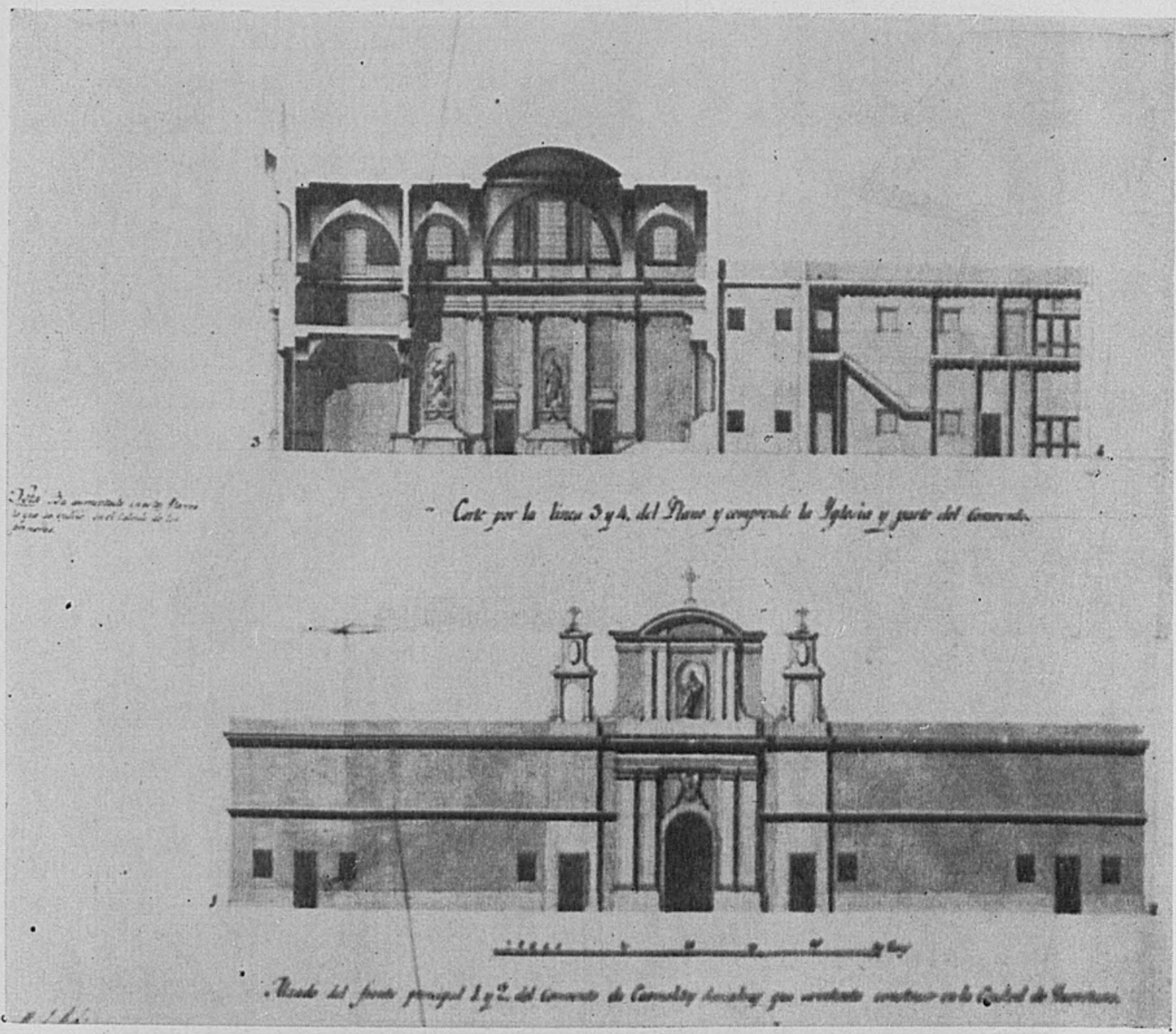

5. Proyecto de Manuel Tolsá para el convento de religiosas carmelitas en Querétaro 
DOI: http://dx.doi.org/10.22201/iie.18703062e.1968.37.862

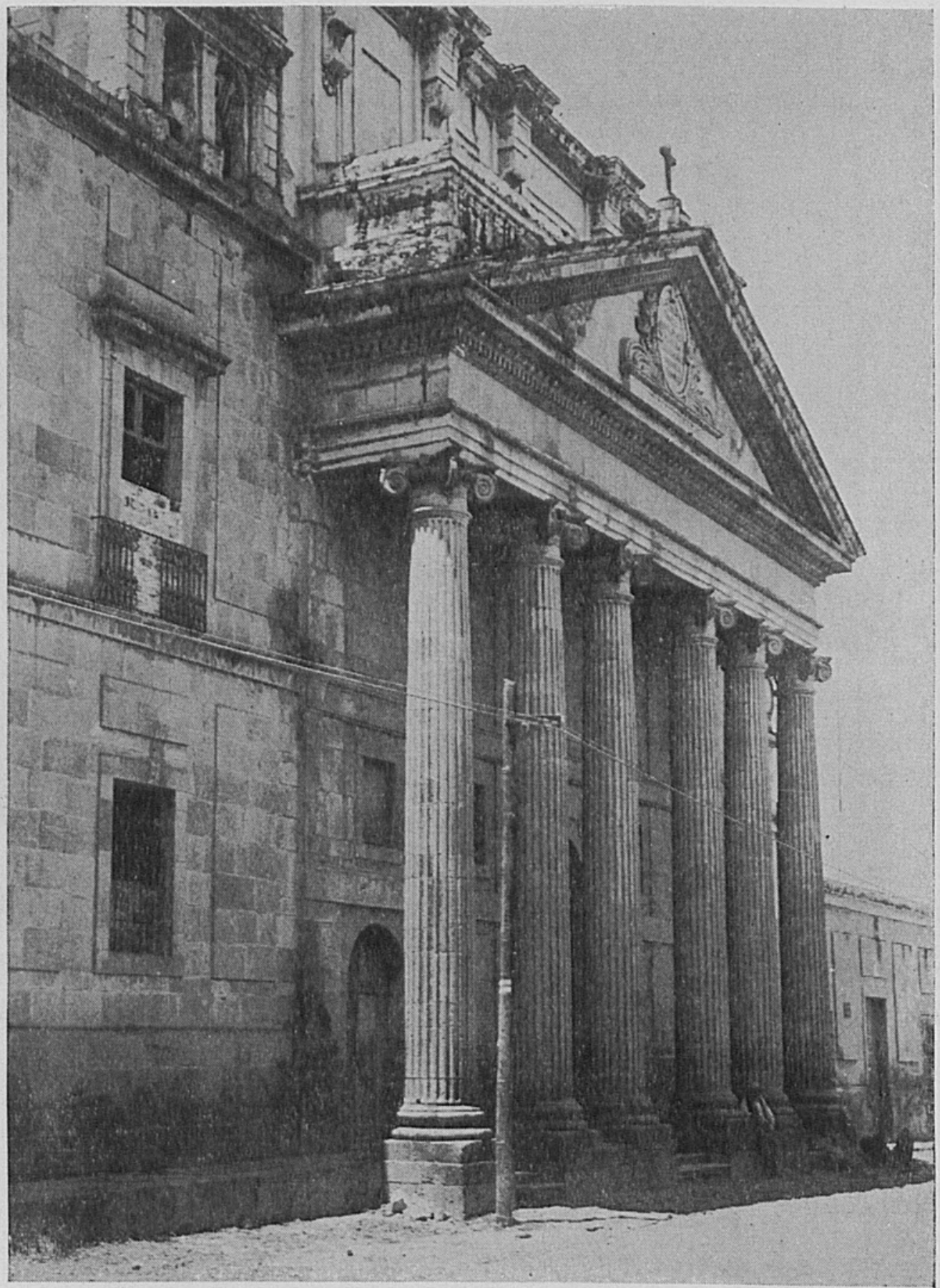

6. Querétaro, Qro. Iglesia de Teresitas 
en la región más alejada del tráfago cotidiano, al fondo del monasterio, situábase una pequeña huerta, la sala de Profundis y el refectorio. Todavía, en la esquina más apartada, en la zona intima del convento, con meditado aislamiento, se proyectaban dos piecesillas para oratorio y retiro.

El costo de la obra, prudencialmente calculado, ascendía a cincuenta y dos mil ochocientos noventa y siete pesos y siete reales.

La mayor parte del presupuesto lo absorbía la mampostería, calculándose a dos pesos y cinco reales la vara cúbica. Una piedra de cantería costaba, en promedio, un peso y treinta y seis céntimos; la puerta de la iglesia se calculaba en cien pesos y el fierro y la manufactura de cinco rejas para el locutorio y coros, alto y bajo, se calculaba en dos mil pesos. A última hora, la marquesa había pedido al arquitecto que alargara en seis varás el largo de la iglesia, importando este aumento, en construcción, la cantidad de cuatro mil pesos. ${ }^{17}$

Mas el neoclásico proyecto de Tolsá no llegó a realizarse; la primera piedra para el edificio se colocó el 24 de junio de 1803, pero por alguna razón no se siguió la obra con arreglo a sus planos, sino con una traza diferente, principiándola un arquitecto de nombre Ortiz y continuándola, hasta su conclusión, en 1807, don Francisco Eduardo Tresguerras, ${ }^{18}$ en un neoclásico menos académico.

17 A.G.N., Historia, vol. 77, f. I10.

18 Frias y Frías, V., Leyendas y tradiciones queretanas..., p. 308.9. 